\title{
Categories of intuitive reasoning and GeoGebra 3D: an experience with Brazilian students
}

\author{
Renata Teófilo de Sousa, Francisco Régis Vieira Alves and \\ Italândia Ferreira de Azevedo \\ Federal Institute of Science and Technology of the State of Ceará, Fortaleza, Brazil
}

\begin{abstract}
This work presents the result of the application of a didactic sequence designed to understand the concept of the Cavalieri's Principle, supported by the GeoGebra application in its version for mobile phones - 3D Calculator. For this study, the Theory of Categories of Intuitive Reasoning, by Efraim Fischbein, was used as a conceptual basis. The objective of this work was to elaborate and develop a didactic sequence aiming to subsidize the learning of the Cavalieri's Principle from GeoGebra, as a way to help the student in the construction of geometric reasoning, through visualization, perception and intuition. The methodology of this work is qualitative research, exploratory type, being carried out from a didactic sequence developed in two meetings remotely, due to the scenario of the COVID-19 pandemic. The target audience of this research is a group of students aged 15-17 years from a public school in Fortaleza - CE, Brazil. In summary, it is pointed out that the intuitive reasoning categories mobilized from the use of GeoGebra have great potential to stimulate the evolution of the student's geometric thinking, through the development of perception, intuition and geometric visualization.
\end{abstract}

\author{
ARTICLE DETAILS \\ LUMAT General Issue \\ Vol 9 No 1 (2021), 622-642 \\ Received 8 June 2021 \\ Accepted 17 July 2021 \\ Published 19 August 2021 \\ Pages: 21 \\ References: 17 \\ Correspondence: \\ renata.sousa1@prof.ce.gov.br \\ https://doi.org/10.31129/ \\ LUMAT.9.1.1618
}

Keywords: Categories of intuitive reasoning, Cavalieri's Principle, GeoGebra 3D

\section{Introduction}

Geometry - Plane, Spatial and Analytical - is part of the curriculum component of High School, being a requirement for the cognitive evolution of students in this stage of teaching. According to the Common National Curriculum Base (BNCC) the skills necessary for a global understanding of Geometry refer to the interpretation, construction of models, solving and formulating mathematical problems involving notions, concepts and spatial procedures (Brazil, 2018). Geometry, even with its visual and concrete character, as several everyday objects involve it, is still an area in which the high school student faces difficulties in assimilation, and this is pointed out by authors as Alves \& Borges Neto (2011), Alves \& Borges Neto (2012), Oliveira \& Leivas (2017), Cunha \& Aguiar (2019).

Regarding the mathematical object under study in this article - the Cavalieri's Principle - there is an existing problem in the teaching and learning process, where this subject is presented in a ready-made, mechanized way, not exploring the 
visualization and perception necessary for its understanding, in some occasions due to lack of depth on the part of the teacher. According to Paterlini (2010) the Cavalieri's Principle is commonly presented without demonstration, as a way to avoid the obstacles of showing this theory early. Difficulties are concentrated in a single assertion, which is admitted as plausible upon good argumentation and explanation by the teacher.

Starting from this premise and taking into account the importance that the Cavalieri's Principle has for the student's understanding of the calculation of volumes of geometric solids, how the student can understand and develop geometric concepts about volumes using the Cavalieri's Principle, from a visualization perspective and intuitive reasoning? To this end, the contribution of GeoGebra was used, as it is a software that is easy to access and use, being efficient for teaching Geometry, among other areas.

GeoGebra is a resource that comes to add to the teacher and facilitate their practice, being efficient in the presentation of complex assimilated content, where the virtual environment allows the visualization and manipulation of its elements and constructions. Mariotti \& Fischbein (1997, p. 221) bring that "the definitions of basic geometric figures are not merely conventions in the field of purely arbitrary facts; elementary geometry and geometric concepts are deeply rooted in common experience". Thus, the software has the potential to stimulate the student's intuition and geometric reasoning, enabling deduction and interaction through content experimentation. In addition, according to Breda, Trocado and Santos (2013), with $3^{\mathrm{D}}$ functionalities, GeoGebra makes the representation of elements in space more accessible, contributing to understanding through visualization.

The objective of this work was to elaborate and develop a didactic sequence aiming to subsidize the learning of the Cavalieri's Principle from GeoGebra, as a way to help the student in the construction of geometric reasoning, through visualization, perception and intuition. To this end, this work brings the Theory of Intuitive Reasoning Categories, by Efraim Fischbein, which guides the observations raised from the applied didactic sequence, which seeks to understand how the student's geometric reasoning is consolidated.

The methodology of this work is qualitative research, exploratory in nature and had as target audience a group of students aged 15-17 years, high school students in a public school in Fortaleza - CE, Brazil. The two meetings held for the application of the didactic sequence and data collection took place virtually, due to the scenario of 
the COVID-19 pandemic, which changed the format of classes and the routine of schools around the world.

In the next sections, historical, epistemological and didactic aspects about the Cavalieri's Principle, the Theory of Intuitive Reasoning Categories associated with GeoGebra and its relevance to this article, as well as the applied methodology with their respective results and considerations of the authors, will be addressed.

\section{Historical, epistemological and didactic aspects about the Cavalieri's Principle}

Bonaventura Cavalieri (1598-1647) was an Italian mathematician and priest, who brought several contributions to the development of Mathematics, in the areas of Trigonometry, Astronomy, Geometry and Optics, being considered one of the precursors of Integral Calculus (Hoffmann, 2018). However, the core of this work focuses on the object of study that bears its name, the postulate known as the "Cavalieri's Principle", commonly used in problems involving the calculation of the volume of solids.

The statement of Cavalieri's Principle states that "Two solids, in which every secant plane, parallel to a given plane, determines surfaces of equal areas (equivalent surfaces), are solids of equal volumes (equivalent solids)" (Dolce \& Pompeo, 2005, p. 165). It is noteworthy that although the demonstration of the Cavalieri's Principle is not easily understood by high school students (Cunha \& Aguiar, 2019), the presentation of practical examples should be considered to illustrate it and prove its veracity, providing the development of geometric reasoning in an intuitive way, based on visualization.

Plane and Spatial Geometries are directly related, as the postulates of one serve as a basis for understanding the nature of the other. Based on this relationship, Alves \& Borges Neto (2011) point out that the subject (student) relies on mental images, experienced in their daily lives based on objects from the physical world to understand Geometry. On the other hand, when this subject undergoes some formal training, it is expected that he will manifest geometric perceptions such as linearity, regularity, depth of the figures. Regarding depth, this deserves to be highlighted, because, despite displaying an intuitive bias, in general, in the teaching of Spatial Geometry, the representations are displayed on the plane, conveying an illusory impression of belonging to three-dimensional space. 
From an epistemological point of view, it is known that many students have difficulties in understanding geometric problems (Oliveira \& Leivas, 2017; Cunha \& Aguiar, 2019), for not having well-developed visualization and perception skills of geometric representations. Oliveira \& Leivas (2017, p. 110) state that "Geometry requires the activity of the gaze with the understanding that an image drawn on a plane is the representation of a three-dimensional object”. Thus, it is noted that there is an obstacle to overcome, regarding the articulation between the two-dimensional (2D) and three-dimensional (3D) dimensions, that is, the articulation of the figure in space and its representation.

Cunha \& Aguiar (2019) mention that the excess of algebraic thinking within geometry ends up creating cognitive barriers for the student, as such reasoning can often be disconnected. It is important to consider that geometric visualization is also an exercise that develops the student's reasoning, helping him to understand geometric properties and solve problems. Also, according to the authors, the Cavalieri's Principle is not well explored in textbooks, being insufficient in several aspects, such as the presentation of ready-made formulas, for example.

Didactically, by exploring the Cavalieri's Principle, students could develop a different perspective on space and form. By understanding Cavalieri's idea geometrically and by accepting these principles as obvious, intuitively, many measurement problems that normally require more advanced calculation techniques can be solved (Cunha \& Aguiar, 2019 as cited in Eves, 2011).

Considering these aspects, it was decided to develop a didactic sequence to work on the student's geometric reasoning based on visualization and intuition about the Cavalieri's Principle, using the dynamism of GeoGebra. For this development, the following section presents an overview of the categories of intuitive reasoning and makes a parallel of its mobilization from the use of GeoGebra software, as a support to the understanding of the student's geometric reasoning from the visual field.

\section{Theory of Intuitive Reasoning Categories and GeoGebra}

According to Pais (1996) there are four fundamental elements that directly influence the learning of Euclidean Geometry, whether flat or spatial, which are the object, the concept, the drawing, and the mental image. Regarding these four elements, it is crucial to add the semantics present in geometric language within problems. Thus, still according to the author, such objects and their respective representations by drawing interfere in the procedural reasoning and in the construction of the student's 
geometric knowledge.

Fischbein (1993) points out that geometric objects have two essential components, which are the concept and the image, which conceive the learning of geometry in a considerable way. Furthermore, the passage from the experimentation stage to the abstraction requires a balance between such components, which in turn can be provided by the use of mathematical software, as is the case of GeoGebra, presented in this work.

Alves \& Borges Neto (2011) also point out about Fischbein's perspective that geometric figures constitute a mental entity, elaborated from geometric reasoning, in which a figure is different both from its formal definition and from its mental image and in turn it is supported by a sensory perception of a particular given representation. The authors still bring that:

[...] we can conceive and compare the course of the evolution of a student's reasoning with a teacher. The first, when knowing a subject for the first time, does not yet have sufficiently developed familiarity to deal with formal definitions of this content. Thus, it will rely predominantly on intuitive reasoning. During evolution and in the successive advancement of their mental stages of learning, the student, gradually, generalizes, systematizes, and synthesizes the fundamental ideas involved in that subject. In this way, the subject advances to logical and mathematical reasoning. (Alves \& Borges Neto, 2011, p. 42).

That is, the student's reasoning about a new subject initially starts from intuition and based on his perceptions, he starts to conjecture his ideas, formalizing them in a line of reasoning that makes sense to him. Still with regard to intuition, Fischbein \& Gazit (1984) state that the term 'intuition' means, "basically, a global, synthetic, not explicitly justified assessment or prediction. Such global cognition is felt by a subject as self-evident, self-consistent, and hard questionable.” (Fischbein \& Gazit, 1984, p. 2). Thus, as far as Geometry is concerned, the existing theorems are statements that can be proved, in which their veracity (or not) is guaranteed by a sequence of logical inferences, supported by the structure that starts the model and by other theorems previously demonstrated.

For Fischbein (1982), intuition or intuitive reasoning in geometry can occur in problem solving, since the student is encouraged to analyze, experiment, evolve, abstract, and systematize in order to build their mathematical knowledge, with intuitive structures being essential components of all. form of active understanding and productive thinking. 
In this sense, Fischbein (1983) classifies intuition into categories, considering the relationship between intuition and solution, being divided into affirmative, conjectural, and anticipatory intuitions, described below in this author's perspective.

Affirmative intuitions refer to a representation, an explanation or an interpretation directly accepted by people as something natural, evident, intrinsically significant, for example, if someone asks a student what a straight line is, he will most likely try to draw a straight line or he will show the example of a well-stretched line (Fischbein, 1983).

With respect to conjectural intuitions, the solution aspect is explicit, but it is not clearly involved in a resolution effort. They represent statements about future events or about the course of a certain event. This category represents a preliminary, global view that precedes an analytical and fully developed solution to a problem (Fischbein, 1982). The author exemplifies in his work Intuition and Proof:

It seems intuitively clear that the diagonals in a rectangle are equal, that the shortest path between a point and a line is the perpendicular drawn from the point to the line, and so on. At the same time, these claims can be proven, although no proof is needed and, in fact, it seems quite superfluous. (Fischbein, 1982, p. 11).

With regard to anticipatory intuitions, Fischbein (1982) points out that this category of intuition provides a global understanding of a possible way to solve a problem and, thus, influences and directs the stages of search and construction of the solution. In this case, the student is "in the phase of concrete application of strategies, use of formulas, elaboration of drawings that effectively help to identify a solution" (Alves \& Borges Neto, 2011, p. 44).

Fischbein (1987) in his studies thoroughly analyzes the teaching and learning process by stating that students often face difficulties in their learning, understanding and problem solving at more advanced levels, as their reasoning techniques and strategies are guided by implicit models, sometimes inadequate. Thus, the teacher must seek to identify such models and provide support to the student in correcting their mental models, so that their reasoning is built properly.

In this sense, the GeoGebra software has great potential to develop the student's intuition and geometric reasoning through visual perception. As it is a dynamic geometry software with a $3 \mathrm{D}$ window available in its interface, it allows the visualization of figures in an $x y z$ plane. According to Alves \& Borges Neto (2012), the 
exploration of GeoGebra as a technological instrument enables the visualization of unimaginable situations, when restricted to pencil and paper.

To enable the construction of geometric reasoning, Hohenwarter and Jones (2007) claim that GeoGebra provides a closer connection between the symbolic, manipulation and visualization capabilities of CAS - Computer Algebra Systems -, as well as the dynamic mutability of DGS - Dynamic Geometry Systems - within your interface. "GeoGebra does this by providing not only DGS functionality (where the user can work with points, vectors, segments, lines and conic sections), but also CAS (where equations and coordinates can be entered directly and functions can be defined algebraically and then dynamically changed), for example" (Hohenwarter \& Jones, 2007, p. 127).

Mariotti and Fischbein (1997) argue that there is a link between geometry and reality, but even so, geometry is not an empirical science. However, geometry needs reality to serve as a model to demonstrate its various aspects.

It is a fact that Geometry is present everywhere, which reinforces the need for its understanding to understand the world around us. Thus, according to Oliveira \& Leivas (2017), it is opportune to work with learning situations that encourage the student's thinking to establish relationships between spatial figures and their flat representations, seeking to develop, from their observations, different points of view, building and interpreting their representations. Breda, Trocado and Santos (2013) point out that the alternative of a three-dimensional visualization is presented as a way to facilitate the understanding of concepts by the student, which favors their learning.

From what is exposed in this section, the relevance of the study about the relationship between mathematical intuition and Spatial Geometry is based, since the perception of geometry, through visualization, has the potential to develop the student's geometric reasoning, helping him in construction of mental models suited to their cognitive evolution. The next topic illustrates the application of the didactic sequence, the methodology of this work, which exposes such ideas in a practical way.

\section{Methodology}

For this article, an exploratory research methodology was adopted, delineated by a case study, as a way to observe the applied experiments and to anchor data that allow us to understand how GeoGebra contributes to the mobilization of intuitive reasoning categories in students. According to Gil (2002) the results of a case study are 
presented as hypotheses and not as conclusions.

The research was applied with a group of twenty students, aged 15 to 17 years, attending high school, and coming from a public school in Fortaleza - CE, Brazil. The application took place in two meetings during extra-class time, in which students were invited to participate in a moment of experimentation with the use of dynamic geometry through the GeoGebra software. The meetings took place remotely, due to the current scenario of the New Coronavirus pandemic (COVID-19), using the Google Meet platform. The structuring of the didactic application followed the steps:

1. Presentation of the didactic sequence and establishment of the didactic contract $^{1}$;

2. Availability of constructions in GeoGebra;

3. Manipulation of constructions by students, in search of solutions and construction of knowledge about Cavalieri's Principle.

For data collection, two electronic forms were used, an initial questionnaire to survey the class about their knowledge of GeoGebra and a final questionnaire to capture their impressions and reflections on their learning in the meetings, video recording file of the moment application and photographic record. To preserve the identity of participants in this application, students will have their names represented by Student 1, Student 2, and so on.

The constructions in GeoGebra were made available to the students, as an alternative to optimize time and focus on the manipulation and understanding of geometric properties that would help in the construction of the concept of the Cavalieri's Principle.

\subsection{Application of the didactic sequence}

In the dynamics of the first meeting, a didactic contract was established with the class, presenting the set of guidelines for carrying out both moments. According to Brousseau (2008), the didactic contract consists of a set of expected behaviors from the teacher and students, mediated by knowledge.

In the didactic contract with the class, it was explained that they would solve a didactic sequence, a component of a research, reinforcing that the participation of all

\footnotetext{
${ }^{1}$ The didactic contract, according to Brousseau (2008) is a verbal contract that determines the role of the subjects teacher and student -, places and functions of everyone involved in the didactic situation, in a system of obligations whose reciprocity is necessary, with this relationship being mediated by knowing.
} 
was of great importance. The group was asked to record the encounters through photographs or print screens from the cell phone screen, both from the calculations noted in their notebooks, and from manipulations in GeoGebra. Students were instructed to perform the calculations in their notebook and using the application as a way to compare and reflect on the answers. In addition, they were instructed to use the platform chat or microphone to dialogue, ask and/or validate their answers. Furthermore, it was explained that they would answer two forms, an initial and a final questionnaire, and it was established that everyone would receive constructions 1, 2 and 3 as GeoGebra files (.ggb) via the WhatsApp group.

Then, the didactic sequence was presented, as shown in Table 1:

Table 1. Proposed didactic sequence

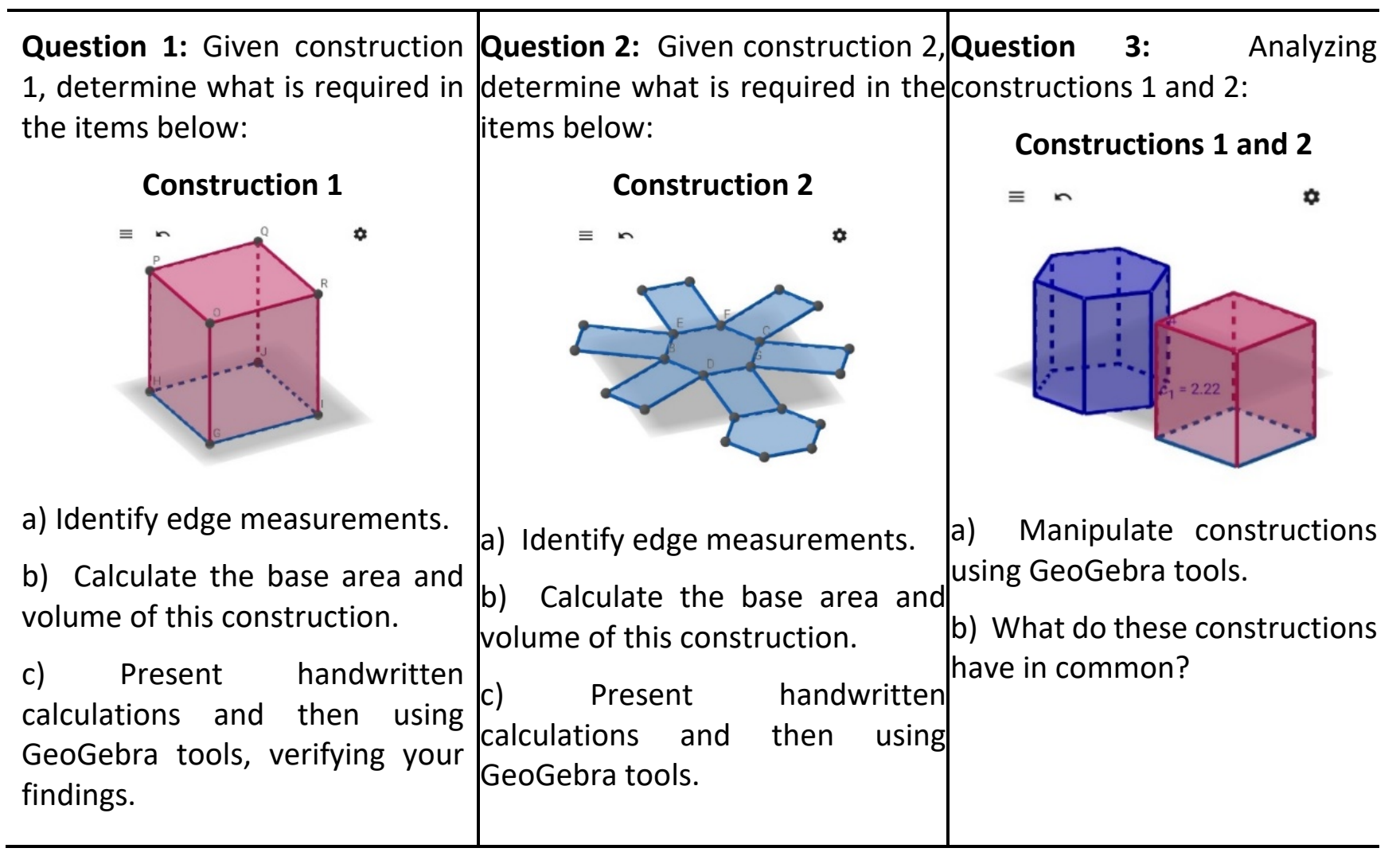

The didactic sequence sought to work on the development of skills such as geometric perception and intuition through the visualization and manipulation of constructions in the GeoGebra - 3D Calculator application. According to Breda, Trocado \& Santos (2013, p. 64) "The possibility of viewing in $3 \mathrm{D}$ seems to be a way to facilitate the apprehension of concepts and to favor the students' learning”.

To get the class acquainted with GeoGebra, the teacher projected her cell phone screen (Figure 1) in the remote classroom, presenting the $3 \mathrm{D}$ Calculator application 
in its smartphone version. Thus, it showed some basic functionality of the application, the algebra window, and the $3 \mathrm{D}$ window.

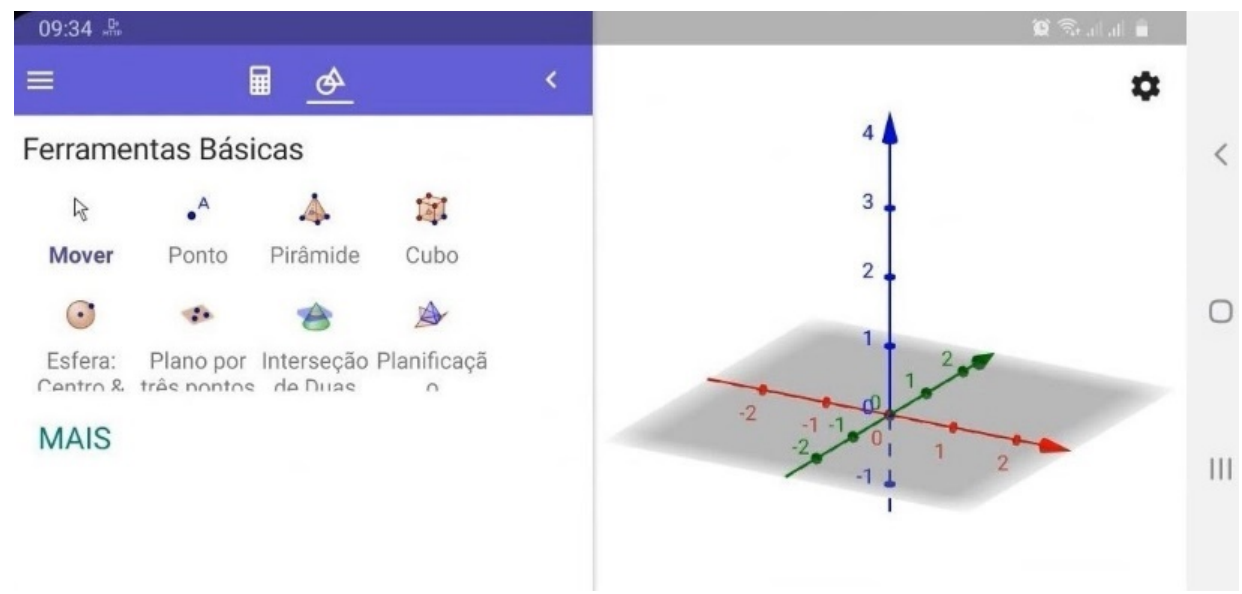

Figure 1. Presentation of the 3D Calculator app for smartphones

Figure 1 shows the initial interface of the $3 \mathrm{D}$ Calculator application, explored by the class. Next, the first question of the didactic sequence was proposed, where construction 1 was made available in (.ggb) format for the group of students.

At first, the students manipulated and explored construction 1 presented within the $3 \mathrm{D}$ Calculator application, through rotation, enlargement and reduction, seeking the necessary information to solve the proposed question.

When asking the class: "Which polyhedron is this?", the initial, possibly intuitive, response was to say, "it's a cube, teacher!", even without the side measurements being presented. After provocations and during manipulation, some students in the group realized that it was not a cube. The clipping of some lines was:

"It is not a cube, as the 'sides' are not all the same" (Student 1)

"Now I saw that it is not a cube, as the height is different from the base" (Student 2)

"It looks like a cube, but it isn't. It's a cobblestone" (Student 3).

According to Fischbein (1982), mental experience is a reproduction of the practical process based on goal-oriented trial and error. The perfect proof has no meaning for the natural empirical way of thinking, justifying why the students referred to the construction as a cube immediately, based on their experiences, without resorting to a demonstration. "To really understand what a mathematical proof means, the student's mind must undergo a fundamental modification.” (Fischbein, 1982, p. 17). 
By manipulating the construction, using the command "distance, length or perimeter", the students were able to find the measurements of the edges, both of the base polygon and of the lateral edges, which correspond to the height of the prism. This can be seen in Figure 2, which corresponds to the presentation of Student 4:

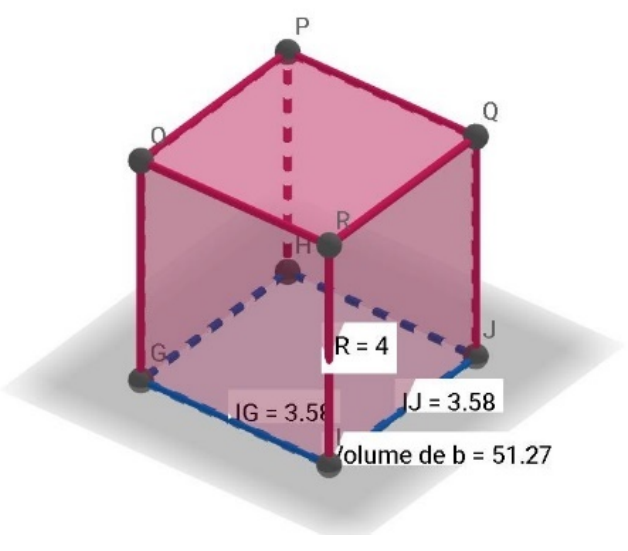

Figure 2. Student 4 Presentation

From the measurements found in Figure 2, the students started to look for the results of the base area and the volume of the construction, based on their previous knowledge and perceptions about the construction.

After dialogue and participation of the class, some students in the group shared their ideas with those present, presenting their perceptions, conjectures and their notes about the construction, listening to the others in an environment conducive to the construction of knowledge.

It is noteworthy that the validation presented by Student 2 was wrong, as he presented the area of the base of the construction using one of the edges of the base and the measure of the lateral edge $(3,58 * 4=14,32)$. Even proving the value of this area in GeoGebra, it was not the answer requested by the question. Fischbein (1993), in his perspective, points out that in mathematical reasoning, material objects - solid or drawings - are only materialized models of mental entities with which the mathematician deals. Thus, a geometric figure is not a mere concept, but a visual image. Therefore, Student 2's mistake was based on an erroneous observation of the image.

After discussion, Student 3 designed his screen, showing the top view of the building in GeoGebra, proving that the base is a square and exposing the respective measurements, as shown in Figure 3: 


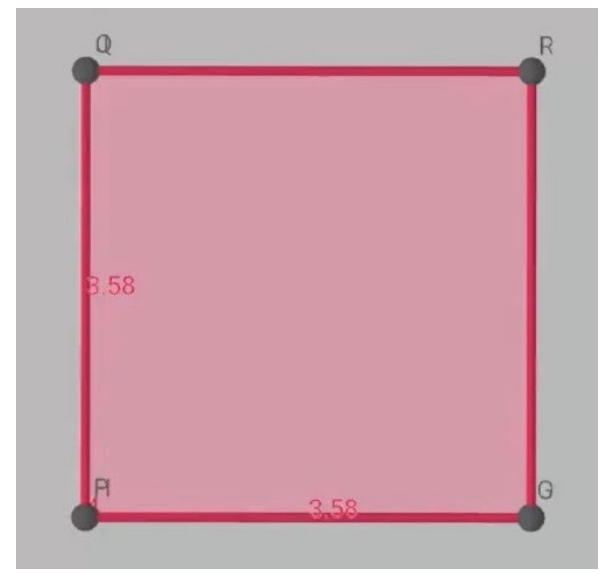

Figure 3. Top view of construction 1 presented by Student 3

Figure 4 shows the comparison between the calculations in the notebook and the proof of the answer based on manipulation in GeoGebra:

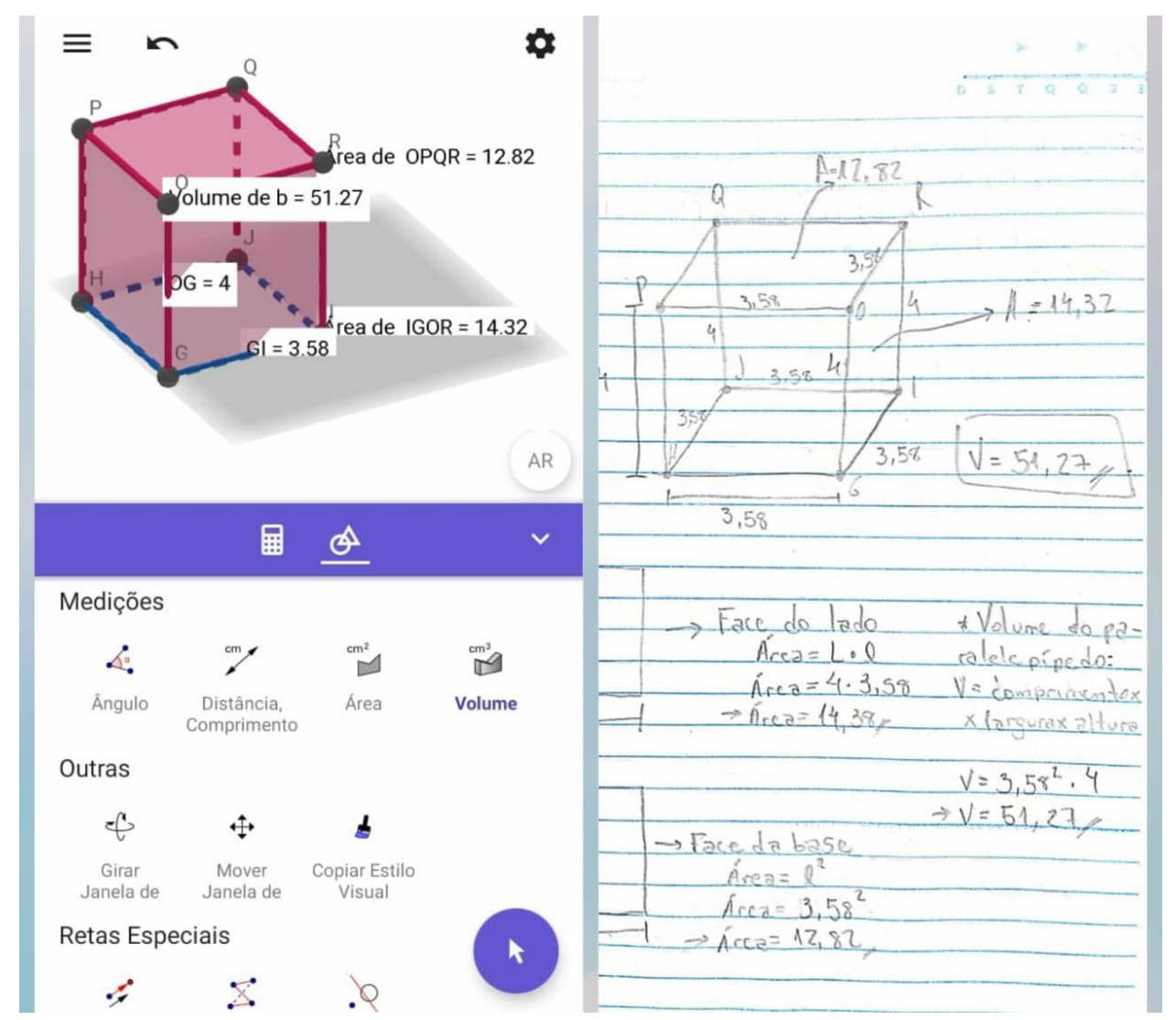

Figure 4. Comparison between manual and GeoGebra responses - Student 3

In Figure 4, it is noted that Student 3, in order to perform the calculations manually, felt the need to visualize the image of the cobblestone of construction 1 , so much so that he scribbled a drawing for better understanding. In this case, according 
to Fischbein (1982) a level of intuitive acceptance occurs in Figure 4, referring to the fact of understanding the universal validity of the statement as guaranteed and imposed by the validity of the proof.

Regarding the second problem proposed, as the class was already familiar with GeoGebra, the process of manipulating the construction and solving the proposed situation were optimized. The discovery of the planning tool aroused enthusiasm and interest. One of the students used the expression "What a genius!" as a demonstration of the reaction when seeing the construction in motion, when opening and closing the plan. In Figure 5 and Figure 6 there is a record of this movement, as well as the recognition of the solid formed:

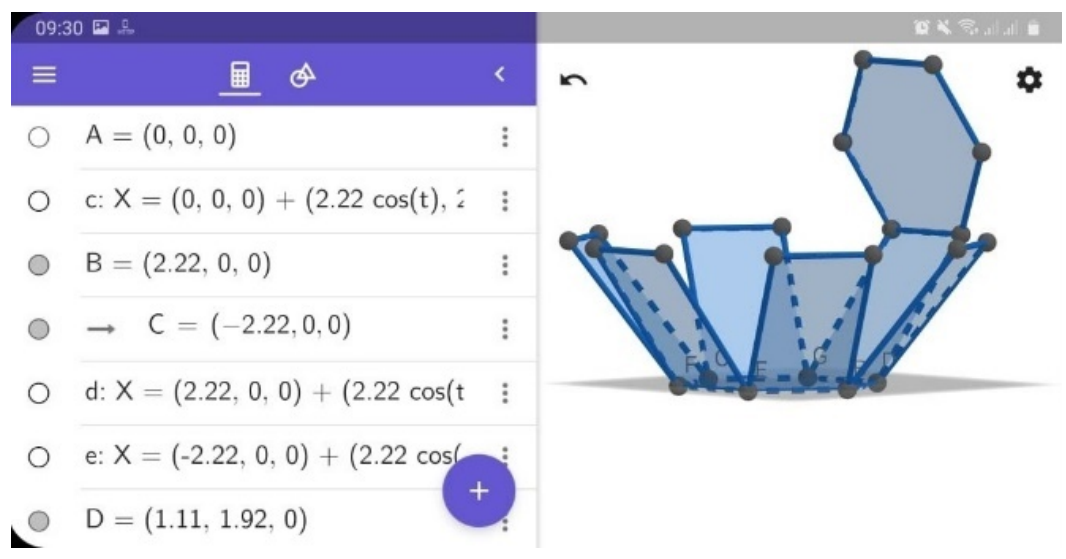

Figure 5. Construction planning movement 2

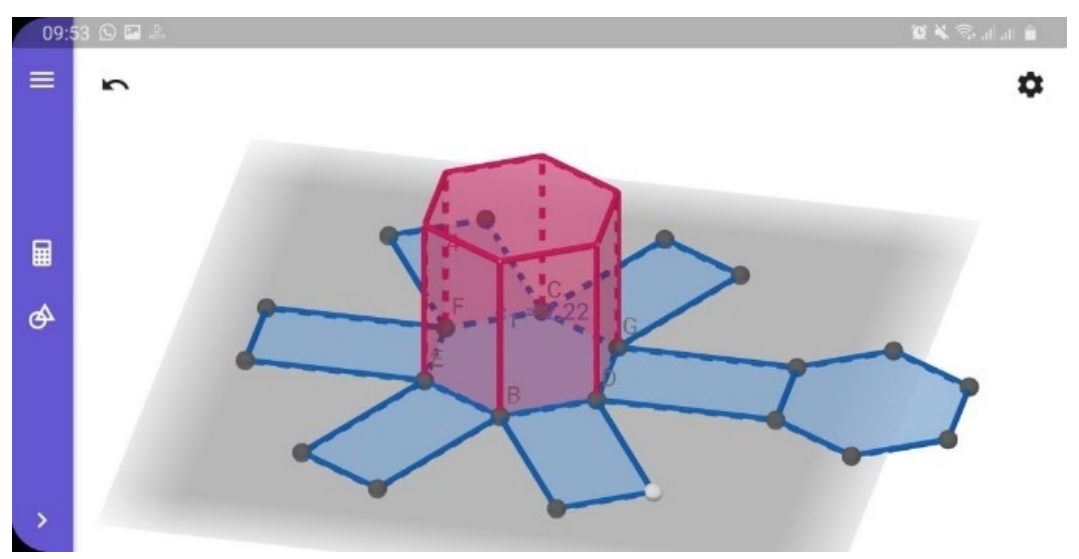

Figure 6. Construction of the flat prism and its 3D sketch

When manipulating construction 2, the students recognized it as a hexagonal base prism and performed the same procedures performed in the situation in question 1, where they discovered the measurements of the base edges and the side edges. Thus, some students in the group have already resorted to what Fischbein (1987) classifies 
as anticipatory intuition, where there is a notion of the steps to be taken to solve the problem and the strategy to be used for that.

However, in the formulation, when elaborating the conjectures to carry out the manual calculation procedures, the students did not remember how the area of a hexagon was calculated. Until a conjectural intuition from Student 2 facilitated the group's insight:

"A hexagon is formed by six equilateral triangles. If I know how to calculate the area of an equilateral triangle, I just multiply the area by 6" (Student 2).

Student 2's speech is marked by the elaboration of conjectures. From the perspective of Fischbein (1987) it is inferred that Student 2 presented a conjectural intuition, as the elements necessary for the solution were already explicit in the construction, but the student still cannot visualize the solution.

After discussion and an intuitive structural understanding of the mathematical formulas for calculating the area of the equilateral triangle and, later, the area of the hexagon, the students proved the veracity of their manual calculations with the calculator (because it contains decimal approximations) and interacting with the construction in GeoGebra, as seen in Figure 7: 


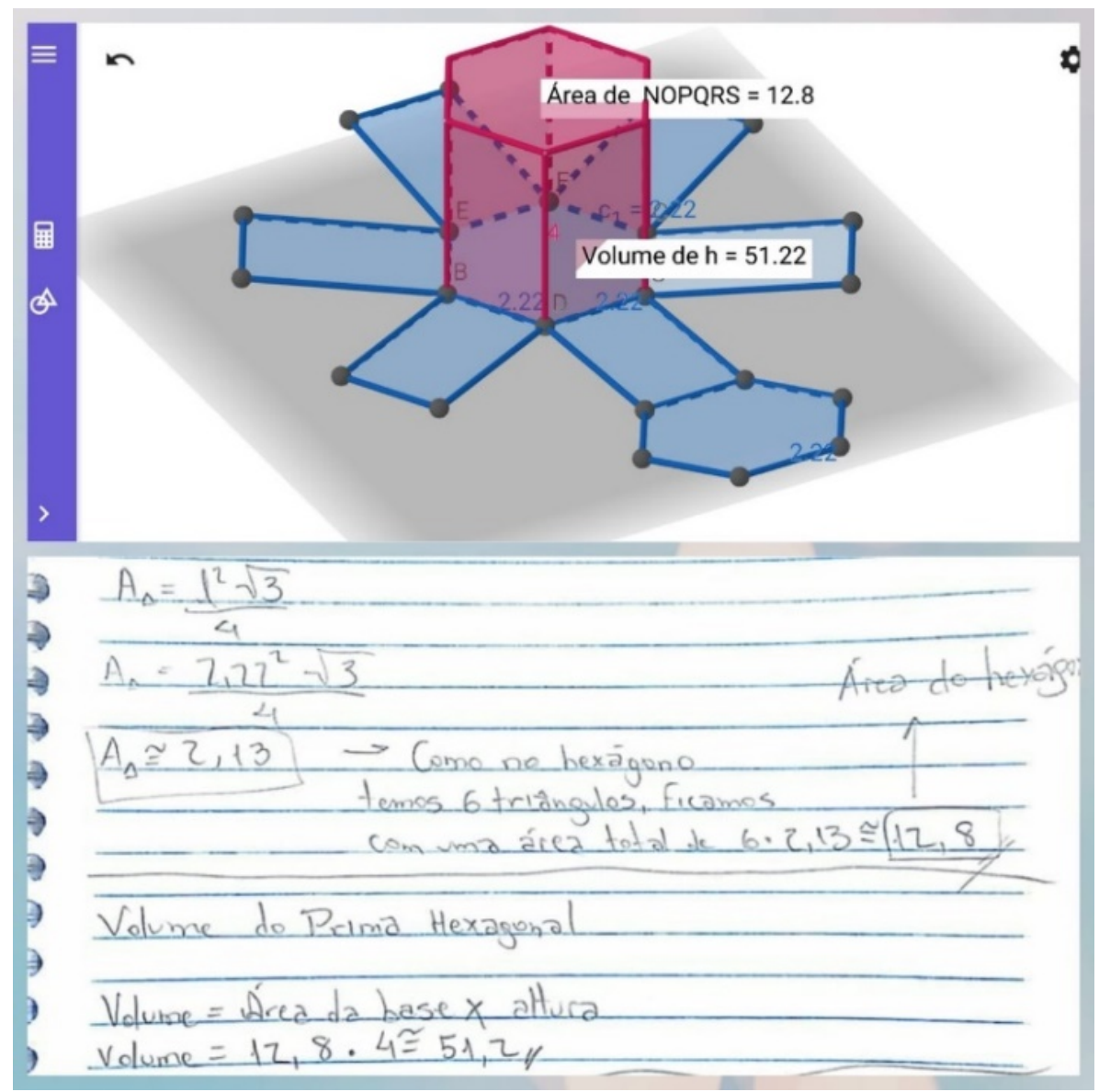

Figure 7. Comparison between manual calculation and result in GeoGebra - Student 3

Fischbein (1993, p. 141) points out that "the properties of geometric figures are imposed by, or derived from, definitions in the domain of a given axiomatic system". From this point of view, a geometric figure also has a conceptual nature. In Figure 7 , conceptually assuming that the construction corresponds to a hexagonal base prism, verifying the base and lateral edge measurements, we found, through a set of procedures, base area and volume values, as numerically equal results, considering the rounding of decimal places.

And finally, the third question of the didactic sequence was presented, which seeks to stimulate the conception of the generalization of the Cavalieri's Principle. When viewing constructions 1 and 2 (side by side), the students were instructed to observe and manipulate them, modifying the base and height edge measurements, always giving the same value to these edges in both constructions and watching your results. See the example of this modification in Figure 8, where Student 2 modifies the height: 


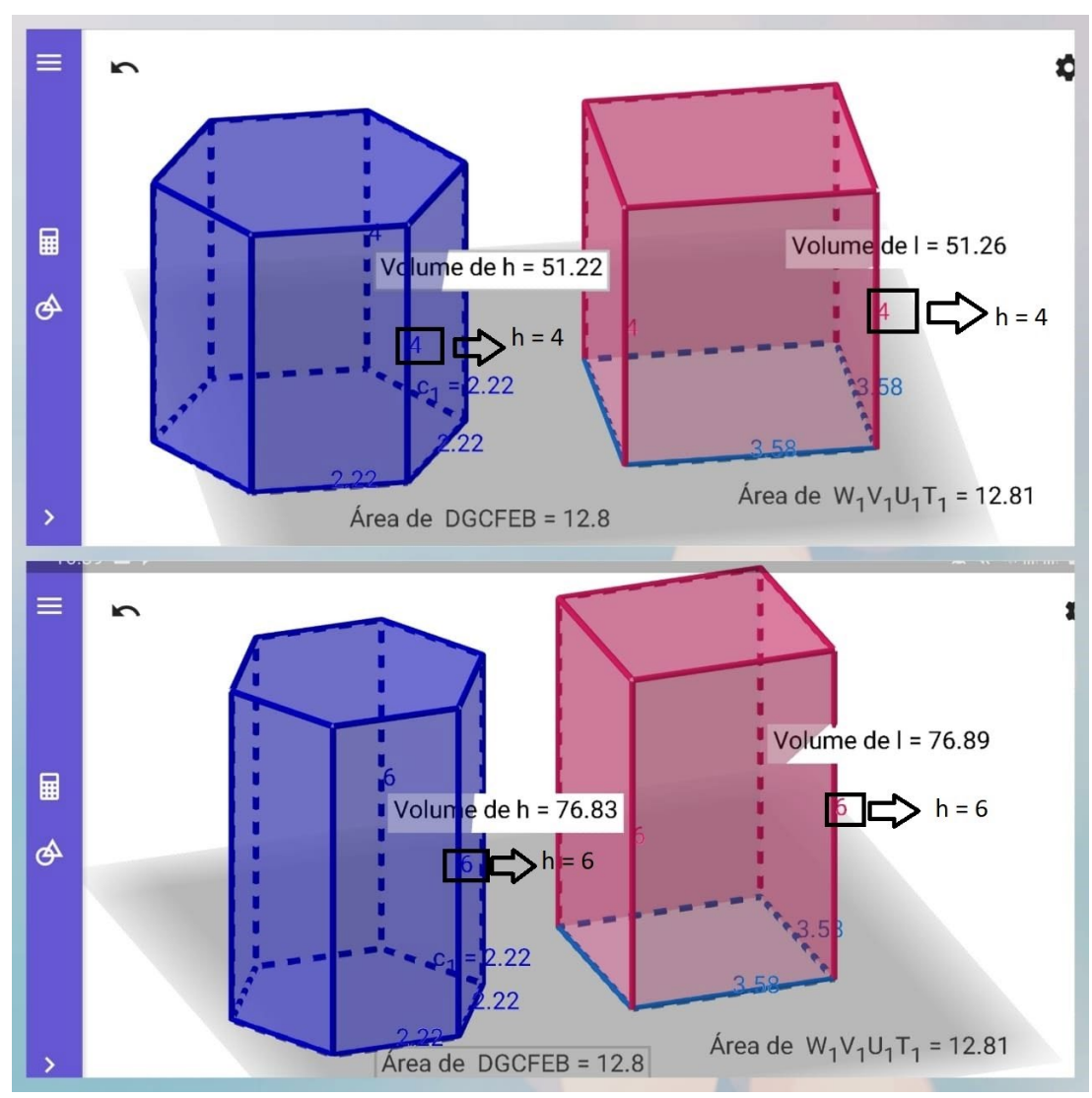

Figure 8 . Manipulation of constructions 1 and 2 by Student 2

In Figure 8, the students observed that when manipulating the height measurement in both constructions, but leaving the same measurement in the two solids, the volume was also the same, with minimal differences arising from the truncation of decimal places. The question "what do these constructions have in common?”, asked by the teacher, was answered by some participants:

"Teacher, the base area is the same" (Student 1 ).

"Ah, I remember that in the last class we had done the calculations and the height was the same" (Student 2).

"Teacher, the base area is the same, the height and the volume too!" (Student 3).

After requesting the manipulation and modification of the measurements of the two constructions, the students reached the conclusion that "the volume always remains the same". After verifying these observations, a moment of conceptualization carried out by the teacher began, in which it was sought to verify whether the objective of the activity was actually achieved. At this point, the teacher significantly synthesized everything that was exposed in the previous steps, formalizing the mathematical character of what was validated by the students. 
The teacher presented a formal definition about the object proposed in the question, which in this case was the Cavalieri Principle. This definition was taken from the textbook adopted by the school, Conexões com a Matemática collection - volume 2, illustrated in Figure 9:

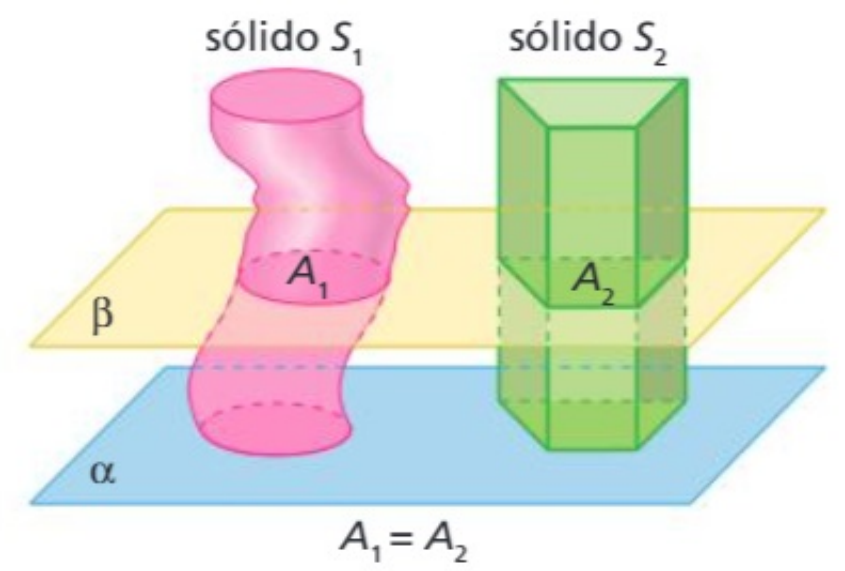

Figure 9. Illustration of the Cavalieri's Principle, by Leonardo (2016, p. 117)

The definition given in the book says the following: "Given two solids $S_{1}$ and $S_{2}$, supported in a plane $\alpha$ and contained in the same half-space, they will have the same volume $V$ if every plane $\beta$, parallel to $\alpha$, sections the two solids according to plane regions of the same area $(A)$ " (Leonardo, 2016, p. 117).

After presenting the definition of the Cavalieri's Principle, the teacher related it to the proposed didactic sequence, considering that the intention of this application was to provide an opportunity for an investigation, experienced by the students, through the visualization and perception made possible by GeoGebra in the construction of geometric reasoning and understanding of this subject.

\section{Results and discussion}

The results presented in this section were collected from the application of the didactic sequence carried out in the meetings, characterizing the students' impressions about the use of GeoGebra and its usefulness for the understanding of Geometry, culminating in learning about the Cavalieri's Principle. After acceptance, the initial questionnaire was applied, which provided us with the following results:

- In the question “Do you know GeoGebra?” $76.2 \%$ of participating students said yes, against $23.8 \%$ who said they did not know; 
- When asked if they had ever used GeoGebra to solve math exercises, 76.2\% said they had never used it, while $23.8 \%$ had ever used the software;

- $81 \%$ of participating students said they had difficulties in drawing spatial figures by hand and in understanding them without a drawing or visual representation;

- $100 \%$ of participants said they are interested in studying geometry in a more dynamic way.

Student responses show us that a significant number know or have heard about GeoGebra. However, a significant number of students have never used the exercise solving software. According to Fischbein (1993, p. 141) "The material objects - solids or drawings - are only materialized models of the mental entities with which the mathematician deals", so if these mental models are not well developed and linked to their mathematical concepts, there is difficulty in their understanding and transposition of the mental representation to paper, which was characterized in the students' speech. The answers show an interest in learning geometry in a more dynamic way.

Regarding the final questionnaire, we sought a subjective view of manipulation in GeoGebra. When collecting the students' opinion, we found that $75 \%$ of the students marked the option "I found it very interesting", while $25 \%$ marked "I found it reasonable". No student marked the alternatives "I found it very difficult" and "I found it uninteresting". Thus, it can be inferred that GeoGebra was a resource that caught the attention and aroused the interest of a significant portion of the participating students. When asking them to justify their answer about this manipulation, we bring the clipping of some lines:

"I found it a great subject, a tool that helps a lot" (Student 1).

"It produces dynamic knowledge, which makes learning effective" (Student 2).

"I found it a little difficult, as I had never used it" (Student 3).

"It's a little difficult to use the cell phone" (Student 4).

"I really enjoyed the class and managed to absorb several things, I learned a lot" (Student 5).

"It is very practical and simple, very easy to use and very useful too" (Student 6).

"I found it very interesting to discover areas, volumes, edges and base" (Student 7).

"I had never used it, I thought it was AMAZING" (Student 8).

"I think that after you learn how to handle yourself, it is very practical, and it certainly helps and encourages mathematical studies a lot" (Student 9).

"I found it very simple, but I need more time using the program to improve it was something new, it was interesting after the training" (Student 10). 
The report of these students shows the importance of considering subjective elements such as attention, interest, emotion and even memory in the learning process, constituting their cognitive context. In this sense, the cognitive processes in student learning were constituted as theoretical assumptions arising from the student's own mobilization in learning. Thus, as a way to enhance learning conditions, it is important to encourage active student participation, seeking to develop their role in the construction of their knowledge.

With this application and data collection, the mobilization of intuitive reasoning categories helped in the construction of this new knowledge, which was acquired from the student's geometric perception and visualization, when investigating the solution of the didactic sequence through their mathematical knowledge and reasoning intuitive geometric design. About the content reviewed or learned in this application, some of the most common responses collected were:

"I reviewed the area of the equilateral triangle, prism volume and also learned the Cavalieri's Principle" (Student 1).

"Cavalieri's principle, area of the equilateral triangle and much more" (Student 2).

"Area, volume, spatial figures, planning" (Student 3).

"Handling GeoGebra" (Student 4).

In a subjective analysis of their speeches, it can be seen that GeoGebra enabled the development of the student's reasoning ability, as this student thought, simulated and elaborated strategies, verbalizing ideas and conjectures and learning from their own perceptions. It is understood that the intuitive categories were mobilized and, in a future perspective, can be improved as the use of GeoGebra is encouraged.

Upon concluding that the volumes of any prism, with equal base area and height, were also equal, the students reached the goal of the didactic sequence. Thus, the search for a solution generated a satisfactory result, providing the construction of knowledge.

\section{Final considerations}

With this application we can analyze that the didactic sequence presented and explored with the GeoGebra - 3D Calculator application enabled the construction of knowledge about the Cavalieri Principle, being an approach with satisfactory results. The questions explored enabled an evolution of the students' geometric perception of the mathematical content in question through visualization, reaching the research 
objective, as the students were able to build new knowledge from the exploration of the association between GeoGebra and the questions presented.

In addition, the testimonies of the students confer legitimacy with regard to the contribution that GeoGebra made possible, through the manipulation of constructions, allowing the experimentation and exploration of concepts within Plane and Spatial Geometry, showing itself as a dynamic and interactive tool.

It is noteworthy that the categories of intuitive reasoning were mobilized from a mediation in a oriented way, where the support offered by GeoGebra with regard to the visualization and manipulation of constructions allowed the student to structure conjectures and explore the knowledge that composed the identification of insights verified in the development of the application.

Thus, GeoGebra in its smartphone version - $3 \mathrm{D}$ Calculator - is an alternative resource that is more accessible to students and that can be promoted in schools as a contribution to teaching, not only on the Cavalieri Principle, but also on various topics related to Mathematics.

\section{Acknowledgements}

We are grateful for the financial support granted by the National Council for Scientific and Technological Development - CNPq for the development of this research in Brazil.

\section{References}

Alves, F. R. V., Borges Neto, H. (2011) A contribuição de Efraim Fischbein para a Educação Matemática e a formação do professor. Revista Conexão, Ciência e Tecnologia, Fortaleza, 5(1), 38-54. DOI: https://doi.org/10.21439/conexoes.v5i1.441.

Alves, F. R. V., Borges Neto, H. (2012). Engenharia Didática para a exploração didática da tecnologia no ensino no caso da regra de L'Hospital. Educação Matemática Pesquisa, 14(2), 337-367. Recovered on October 12, 2020, from:

https://revistas.pucsp.br/index.php/emp/article/view/9445/8147.

Breda, A., Trocado, A., Santos J. (2013). O GeoGebra para além da segunda dimensão. Indagatio Didactica, 5(1), 61-84. DOI: https://doi.org/10.34624/id.v5i1.4304.

Brousseau, G. (2008). Introdução ao estudo das situações didáticas: conteúdos e métodos de ensino. São Paulo: Ática.

Cunha, L. G., Aguiar, R. (2019). O cálculo de volume de sólidos usando o Princípio de Cavalieri mediado por materiais confeccionados em impressão 3D. Anais... V COLBEDUCA Colóquio Luso-Brasileiro de Educação, 4(1). Recovered on February 5, 2021, from: https://www.revistas.udesc.br/index.php/colbeduca/article/view/17235/11264.

Dolce, O., Pompeo, J. N. (2005). Fundamentos da Matemática Elementar, volume 10: geometria espacial, posição e métrica. 6 ed. São Paulo: Atual Editora. 
Fischbein, E. (1982). Intuition and Proof. For the Learning of Mathematics, 3(2), 9-18. Recovered on November 11, 2020, from: https://www.jstor.org/stable/40248127? seq=1.

Fischbein, E. (1987). Intuition in science and mathematics: an educational approach. Netherlands: D. Reidel Public, Mathematics Educational Library. Recovered on November 10, 2020, from: https://www.springer.com/gp/book/9789027725066.

Fischbein, E. (1993). The Theory of Figural Concepts. Educational Studies in Mathematics, 24(2), 139-162. Recovered on November 05, 2020, from http://www.jstor.org/stable/3482943.

Fischbein, E., Gazit, A. (1984). Does the Teaching of Probability improve probabilistic intuitions? Educational Studies in Mathematics, 15(17), 1-24. Recovered on November 20, 2020, from: https://www.jstor.org/stable/3482454?seq=1.

Gil, A. C. (2002). Como elaborar projetos de pesquisa. 4 ed. São Paulo: Atlas.

Hohenwarter, M., Jones, K. (2007). Ways of linking Geometry and Algebra: the case of GeoGebra. D. Küchemann (Ed.) Proceedings of the British Society for Research into Learning Mathematics, 27(3). Recovered on January 20, 2021, from:

https://www.researchgate.net/publication/239830609_Ways_of_linking_geometry_and_a lgebra_The_case_of_GeoGebra.

Leonardo, F. M. (Org.). (2016). Conexões com a Matemática 2. 3 ed. São Paulo: Moderna.

Mariotti, M. A., Fischbein, E. (1997) Defining in classroom activities. Educational Studies in Mathematics, 34, 219-248. Recovered on March 5, 2021, from: https://doi.org/10.1023/A:1002985109323.

Oliveira, M. T., Leivas, J. C. P. (2017). Visualização e Representação Geométrica com suporte na Teoria de Van Hiele. Ciência e Natura, 39(1), 108-117. DOI: http://dx.doi.org/10.5902/2179460X23170.

Pais, L. C. (1996). Intuição, experiência e teoria geométrica. Revista Zetetiké, 6. DOI: https://doi.org/10.20396/zet.v4i6.8646739.

Paterlini, R. R. (2010). Os "Teoremas" de Cavalieri. Revista do Professor de Matemática, 72, 4347. Recovered on February 15, 2021, from: https://www.dm.ufscar.br/ ptlini/paterlini_cavalieri.pdf. 